\title{
Envisioning Arctic Futures: Digital and Otherwise*
}

\author{
Barbara Bodenhorn and Olga Ulturgasheva
}

\begin{abstract}
The production of Never Alone (a recent video game incorporating Inupiaq narrative traditions and aesthetics) is one example of how indigenous peoples use digital technologies to spark young people's interest in their own knowledge. Using comparative material from game players in Siberia and Alaska, this article explores interfaces between the knowledge needed to play such games and that required for hunting in real time. Combining attention to decolonizing education and new museology strategies, the authors suggest that the pedagogical impact of such games is strengthened when combined with face-to-face interactions with local knowledge holders. This, in turn, suggests the importance of recognizing the work of the museum as its capacity to animate knowledge, not simply to store it.
\end{abstract}

[Keywords: digital media; education; games; Eveny; Iñpiaq youth; human-animal relations; environmental uncertainty; narratives; new museology. Keywords in italics are derived from the American Folklore Society Ethnographic Thesaurus, a standard nomenclature for the ethnographic disciplines.]

\section{Introduction}

The year 2014 saw the launch of Never Alone, a video game created with the active input of the Inupiat History, Language and Culture Commission and framed around the challenges confronting a young Iñpiaq girl traveling across the tundra with her spirit familiar fox to find the reasons for never-ending blizzards.' According to Ronald Brower, Iñupiaq cultural historian and educator, the motive behind this project was not only to celebrate Iñupiaq history and culture in a twenty-first century digital form but also to promote a sense of resilience among contemporary young Iñupiaq players. ${ }^{2}$

As such, the project reflects the technological innovations of the last several decades that have underpinned the global deployment of digital media and communications technologies to document and preserve local environmental knowledge as well as culturally distinct lifeworlds and livelihoods. For many local peoples, these technologies allow them to impart their knowledge with their own voices. Not only museums but also local educational and governmental institutions and individuals have become involved in such endeavors. ${ }^{3}$

\footnotetext{
This peer-reviewed contribution was accepted for publication in Museum Anthropology Review on June 12, 2018. The work is licensed under the Creative Commons Attribution 4.0 International License. To view a copy of this license, visit http://creativecommons.org/licenses/by/4.0/.
} 
Our engagement with this digital experiment is undertaken through two comparative lenses: that of young Eveny reindeer herders who were encouraged to play and comment on the game and that of a walking project conducted with Barrow middle schoolers in the autumn of 2015. In Siberia and Alaska, adults have identified the need to promote young people's skills to respond creatively to rapidly changing environmental circumstances by building up observational skills, fostering a willingness to think outside the box, and maintaining a spirit of resilient calm. ${ }^{4}$ The first goal of this paper is to contribute productively to local learning concerns, with a particular emphasis on environmental knowledge.

Our larger goal is to ask how this material may contribute to contemporary discussions about the work of a museum. We ask not what a museum can store but what it has the capacity to do. And we ask how the multiple forms in which this work may take place can be better recognized. It is easy to assume that the major work of a museum is to act as a repository of knowledge; the material to come invites readers to consider ways in which a museum may animate knowledge rather than simply collect it.

Thus, this paper resonates with three strands of ongoing theoretical discussions:

- The challenge of democratizing museums, which has been under way since the late twentieth century. ${ }^{5}$ Our discussion turns to two vital issues: access and representation. ${ }^{6}$ As we explore more fully later, we suggest that a focus on the work of a museum is a productive way to move this discussion forward.

- The specific challenges offered by fourth world decolonizing movements. This is the insistence of indigenous peoples that not only should they have a say in how they are represented on the national stage - which often includes virtual technologies - but they should also have more say in how their children learn in ways that do not diminish them. This can include what in pedagogical terms is called place-based learning but just as importantly what might more accurately be called value-based learning.

- Finally, a consideration of these two opening out movements. Decolonizing education and democratizing museums point to what Gable (2009) highlighted nearly a decade ago in his review essay "Museology as Cultural Studies," namely that the democratizing "new museology" brings education and museums together.

In brief, our pedagogical argument is that a combination of teaching tools seems to activate students' sustained interest: just as place-based learning complements classroom discussions, so too do virtual realities animate discussion when combined with face-to-face interaction. This fits well with what we are suggesting is the work of a museum: not only to collect, store, and disseminate information, but also to animate participants' own knowledge in order to deepen it.

\section{The Work of a Museum: Turning Things on Their Heads in Berlin}

Before turning to our own material, we engage with Ann Fienup-Riordan's (1998) collaborative work with Yup'ik elders to discuss what we mean by the work of the museum. In 1994, FienupRiordan accompanied a group of elders from Southwest Alaska to the Ethnologisches Museum in Berlin so they could view the museum's extensive mask archive, which had been created 
approximately a century earlier. As the elders viewed the masks, they were reminded of stories, half forgotten, which they shared with each other. They returned to Alaska to collaborate in the making of the Living Mask exhibit in Anchorage, where objects and recorded stories accompanied each other. It was, in Fienup-Riordan's words, an act of "visual repatriation" $(1999,339)$, which drew enormous numbers of Yup'ik viewers.

Two points emerge from this encounter that we wish to emphasize. The elders did not complain that these masks were the unethical result of the culture grab that characterized so many nineteenth to twentieth century colonial encounters. Instead, they expressed their pleasure that the masks had been conserved in good condition by the museum. Masks have historically been central to Yup'ik ceremonial life. Unlike Tlinget blankets or Kwakiutl coppers, which embody important property, Inuit masks work in a more nonmaterial way. They may have the capacity to animate relations between the wearer and audiences made up of human and nonhuman beings - but it is not the mask itself. Masks can allow access to animated powers and can be easily discarded if no longer in use. If the masks preserved in the Ethnologisches Museum had remained in their original Yup'ik villages, they would most likely not have survived into the twenty-first century. This is not about cultural theft but rather about a nonmaterial relationship with materiality. And it was that relationship that was reanimated during the elders' encounters with masks stored in a museum some five thousand miles away from their homes.' The perspective of the early museum collectors (who fetishized both the thing and its originality) and that of the elders (who did neither) did not have to be in sync for the outcome to be productive.

Both the recognition that things have the capacity to animate knowledge rather than embody it and the recognition that productive outcomes may emerge from troubled power relations are important framing elements in our forthcoming argument.

\section{The Work of a Museum: Escaping the Boundaries on the North Slope of Alaska}

In Barrow, Alaska, the Iñupiat History, Language and Culture Commission was established during the late 1970s, the early years of the North Slope Borough. The remit of the commission, as its title suggests, brings together Iñupiaq ways of knowing - material and nonmaterial-in order to celebrate, conserve, and disseminate that knowledge. Elders conferences, genealogical projects, and artifactual as well as archival collections all constitute part of the commission's mission. Part of that mission includes a striking museum, a library, and a qargi (communal center), but no physical space dominates the whole. Nor are commission-sponsored activities relegated to those spaces. Never Alone directly reflects the commission's goal to foster a lively awareness of and engagement with traditional forms of Iñupiaq knowledge for the development of survival skills of young Iñupiat today. As we discuss, the genesis of the video game itself draws on depictions of material culture as well as some of the stories associated with particular artifacts. These are most prominently displayed in the optional extra segments of the game-segments that draw equally from artifactual history, oral history, and interviews with young hunters active on the North Slope today. Serious effort has been made neither to silo any one particular form of knowledge nor to fetishize any particular site where that knowledge may be accessed. The commission's commitment to engaging with cultural knowledge in all of its forms thus underpins the second element of what we consider the work of a museum. 


\section{Background}

Iñupiat - the autochthonous residents of the North Slope of Alaska-have flourished as hunters and whalers for millennia. Since the establishment of the home-rule North Slope Borough, they have established productive relations with many knowledge experts - scientists, teachers, and others - and have institutionalized the documentation of their own knowledge. ${ }^{10}$ Nonetheless, as Brower noted previously, with the rapid spread of English communications technologies and the steady influx of residents from outside the region, there is concern that crucial aspects of Iñupiaq knowledge are not being passed on. Thus, a number of recent Iñupiaq initiatives are designed not only to re-recognize the value of Iñupiaq knowledge but also to make it accessible to young people both in and beyond the classroom.

The Eveny, or Lamuts, are one of the Tungus-speaking groups, about half of whom are scattered around the Arctic regions of the Russian North (see Vitebsky 2005; Ulturgasheva 2012, 2014, 2016). The Eveny involved in our discussion come from two communities in northeast Yakutia, the villages of Sebyan and Topolinoye. Approximately half of the Eveny in both villages are engaged as nomadic hunters and reindeer herders and move together with their families around vast territories of reindeer pastures on an annual basis, while the other half live in the villages as pensioners, schoolchildren, and village administration employees. We felt that their views on Never Alone would be particularly enlightening due to the striking resonances and notable differences between Eveny and Iñupiaq lives in the twenty-first century.

\section{Genesis of the Game}

The game was conceived and created by Iñupiaq community members with a significant history in education (such as Ronald Brower, Fannie Akpik, and Joe Sage) in cooperation with IT and digital media specialists. It was funded by CIRI, an ANCSA Corporation based in Anchorage. Ron Brower is Professor of Iñupiaq Studies at the University of Alaska, Fairbanks and one of the leading Iñupiaq creators of the project. In a promotional interview (Brower 2014), he noted that many young Iñupiat are spending more time with their computers and less time participating in subsistence activities. "They are members of the Xbox generation." The images they are confronted with on a daily basis emerge from the media centers of the entertainment industry. There is general concern among the elder generation that critical Iñupiaq values are in danger of being lost. "This is a way to transfer some of the knowledge from my generation to theirs," Brower continued, hoping that it would "give insight as to the way Inupiat think-about self-sufficiency, innovation, and thinking outside the box." Such use of digital multimedia resonates strongly with another Iñupiaq initiative to reform local education, namely Jana Harcharek's Iñupiaq Learning Framework, which was officially adopted by the North Slope Borough School District as a set of guidelines in 2010. ${ }^{2}$

The story line centers on a young girl who, with her arctic fox spirit familiar, must overcome a series of challenges presented by both the spirit and the natural worlds. As players master each level, supplementary short visuals that provide further cultural and historical material become 
available. Most of these are presented as first-person narratives, whether telling stories that have come down the generations or recounting personal experiences such as getting caught on the ice.

The visuals, music, and supplemental cultural information combine in a way that is both dramatic and clearly Inupiaq. The purposes as described by the creators of the game were multiple: to provide a medium that would encourage young people to learn-and value - stories they might not otherwise hear; to foster an awareness of the creativity and flexibility that is required for survival in the Arctic; and to encourage a way of thinking in which humans, animals, spirits, and environment are separated out with difficulty. All of these reflect Iñupiaq ways of knowing; none features in Alaska's core curriculum - although they are at the heart of the Inupiaq Learning Framework. Thus, these endeavors are both concerned with the questions of who controls and orchestrates the educational process (inside and beyond the classroom) and the process of producing and distributing aesthetic representations and imagery of Iñupiaq culture. The people with whom we talked about these challenges are clearly thinking outside the conventional educational box but in a way that expands mainstream knowledge practices..$^{13}$

\section{What We Did}

To consider the potential promises as well as the limitations of Never Alone in relation to the goals set out by its creators, we engaged with local users of the game. In Barrow, Bodenhorn talked to school administrators, a few middle school students, a few young parents who were concerned about the inclusion of cultural learning in their children's educational lives, and a few slightly older parents - all of whom were digitally active. Ulturgasheva invited a group of young Eveny reindeer herders to play, assess, and discuss the game in Siberia.

Everyone Bodenhorn spoke with in Barrow had heard of the game. The young adults, who all admired the graphics, had mixed reviews in terms of the game's playability. Several referenced the supplemental additions that reflected real-time Iñpiat discussing issues and events of particular importance to the region. This is an important point, which resonated strongly with the reactions of students across the full range of projects Bodenhorn has been involved with since 2006. Whether in the form of digitalized interviews, classroom visits, local experts accompanying students on field trips, student visits to elders' homes, or exposure to archives, students from both middle school and high school have shown intense interest in the opportunity to engage with firsthand accounts of local experience. This is a point to which we will return.

\section{Playing the Game}

\section{Feedback from Eveny Youth}

Ulturgasheva, who has conducted ethnographic research among Eveny youth for more than a decade (see Ulturgasheva et al. 2014, 2015), asked young reindeer herders to play the game and get back to the us with their feedback on it. The young Eveny were fascinated by the Iñupiaq imagery of the Arctic, which resonated with their own visual perceptions of a native land beautifully lit by sparkling aurora borealis during long winter nights as well as the landscape 
covered with luminous ice, blue snowdrifts, and shiny glaciers. The Iñupiaq protagonist has a parka made of reindeer skin just as any Eveny reindeer herder would have. Next to the girl is her loyal friend and committed fellow traveler, an arctic fox. Misha, an eighteen-year-old Eveny reindeer herder, likened the fox to an animal spirit helper that accompanies a powerful shaman in his or her expeditions to the spirit world. His friend, Kolya, responded that his granddad also had a similar hunting companion, but it was an ermine. According to Misha and Kolya, especially successful and experienced hunters often have their own individual animal spirit helpers assisting them in their hunting trips. In our conversation, they named the animals that local hunters referred to as their own spirit helpers. Their list included a fox, an ermine, a sable, and a snow ram. To have such a helper is a sign of a hunter's luck and an affirmation of special hunting prowess. Among the Eveny, a special relationship between a hunter and an animal spirit helper is often established after a novice catches and brings home his or her first hunted game (see Ulturgasheva 2012, 64-68). The spirit of the first hunted animal then becomes a spirit helper that assists during the course of a hunter's entire life. The digital fox accompanying the girl elicited this resounding response consonant with Eveny understanding of animals as spirit helpers.

Subsequently, the young reindeer herders compared the movement of the girl and her fox with a reindeer herder's journey through a rugged landscape full of malevolent spirits and dangerous predators. The girl's quest also resembled that of a shaman taking flight to a world of spirits, a space of ambivalence, alterity, and transformation. The animist cosmology inspired and thoughtfully captured by the aesthetic vision of Iñupiaq artists and elders was received with appreciation and enthusiasm by the Eveny youth.

One of the episodes of the game that younger herders found particularly captivating was an encounter in which the bear is attacking the girl, who is trying to escape. When questioned about what they had learned from the episode, twenty-one-year-old Anton responded:

What do you mean? It's a game. It is not that it's dead important as it doesn't teach how to really deal with a bear when a bear does go for you. A bear can attack in multiple ways and may happen that it will attack differently - it is never repeating attacks all over again as in this game. And when you are attacked by a bear, it all depends on where you are, what is around, what you have at hand to protect yourself from a bear, and how lucky you are to escape it.

\section{Games and the Unexpected: Eveny Discussion}

Anton succinctly summed up how the Eveny youth viewed the computer game in general. They understood that the game could not capture the full spectrum of human-bear relations, which entails a wide variety of possibilities and multiple contexts. As game players, these young Eveny found themselves constrained by the design and rules of the game. What followed, they felt, was a restriction on personal flexibility; a hunter's success and survival depend not only on calculation and predation but also on personal luck. Among the Eveny, this is an indication of a hunter's even and untroubled relations with the animal spirit world as well as a degree of protection offered to them by ancestor spirits. In addition, the outcome of a close encounter with a predator is affected 
by other factors, such as the geographical location of the hunt and what instruments a hunter has at hand, whether it is a rifle, a knife, or just a sharp stick.

While comparing the game with a real hunt, the Eveny youth recognized that the computer game provides quite a rigid structure of repetitive actions as well as a hypercalculative dimension of the hunt impossible to achieve in real life. That is to say, the game provides a set of calculable expectations and rules for how both human and animal should be expected to behave and react during the encounter. The mark of a good gamer is the ability to see such patterns and thus predict the next challenge waiting for him or her. The mark of a good Eveny herder or Iñupiaq hunter is also to be able to process a great deal of information and to look for patterns in order to generate effective responses but within a much more open-ended range of possibilities. Therefore, gamers must deal with not only the artificially constructed variability and variation of human-animal interactions within a computer game but also encounters following hypercontrolling rules. Apart from visual aesthetics, what makes the computer game attractive is its capacity to generate repeatability of actions and movements, and what points at its restrictive dimensionality is its reduced scope of variability, which provides a contrived structure for close human-predator encounters-i.e., something that cannot be fully structured in a real-life dimension. The latter features of the game produce, borrowing from Nigel Thrift $(2004,588)$, "controlled results." In this sense, the computer game is a result of calculation at each and every point along each and every line of movement. This calculated encounter and interaction might be read as "yet another sign of a more rationalized, calculative world, one increasingly bereft of humanity, a sign taken for a portent of doom rather than wonders" (Thrift 2004, 583). So, we ask how well such calculable, digitally structured, and computerized interactions, movements, and encounters map onto Iñupiaq or Eveny socialities that go beyond humans. In other words, are social relations digitizable? Can the digital reflect the complexity, unevenness, and incommensurability of human and nonhuman personhoods? Can the digital teach the youth about sociality and transmit intimate knowledge about the land of ancestors, subsistence, animals, and life in general in the ways that Brower envisioned?

In regard to the latter, Ulturgasheva asked Anton if experienced hunters could calculate a predator's actions and behavior. He answered, "Yes, but only to a certain extent." The Eveny have a set of practices, taboos, and rituals that address the uncertainty and ambiguity of animal worlds; accumulated knowledge about bears among reindeer herders does indeed revolve around this established set of rules. Features of the circumpolar bear ceremonialism precisely point to these rules that shape and affect humans' relations with the bear (see Hallowell 1926; Kwon 1999; Brightman et al.2012; and others). However, Anton emphasized that humans cannot underestimate the cognitive capacities of a bear or wolf as there is always the possibility for a predator to outsmart a human being. The message is that despite the strength of those conventions, rules, and taboos, people are aware that what is expected may not happen. In this sense, the computer game cannot teach the flexibility needed to face the unpredictability of an immediate interaction or an unexpected encounter.

Although the young Eveny did not engage with the game as a potential teaching tool, we can see how - as with the Yup'ik masks in Berlin - the intense visual engagement acted to animate Eveny reflection, and in turn, this encouraged us to think comparatively about the skills needed for good gaming and good hunting. 


\section{Rules and the Unexpected: The Case of Refugee Bears}

To contextualize the views of the young reindeer herders, we turn briefly to a presentation made in London in 2016 by experienced Eveny reindeer herders. ${ }^{14}$ Here Taiisia Keimetinova and Vasilii Keimetinov elaborated on the ways animals and humans respond to the threatening dynamics of climate change, which, in turn, drive radical environmental changes in the Upper Verkhoyanie mountains in northeast Siberia.

The presenters were particularly concerned with the behavior of Siberian brown bears. According to them, humans are now dealing with different kinds of bears that do not follow established rules concerning human-bear interaction and whose behavior is getting ever more erratic. What had maintained peaceful coexistence and properly sustained boundaries between humans and local bears is now being challenged by refugee bears fleeing areas affected by environmental disasters, particularly vast areas of boreal forest affected by fires in the Russian Far East. One current challenge confronting the Eveny is the unpredictability of these refugee bears, which do not follow conventions, rules, and mutual expectations known and followed by local bears. This is a rapidly changing context of bear behavior that has not been yet accommodated by humans. It is a behavior that is significantly harder to calculate and predict than the actions of a digital bear structured and calculated in advance by an algorithm of the computer game. And the consequences of miscalculation are, of course, more drastic.

Given the Eveny reindeer herders' distress at these rapidly shifting rules and unusual bear behaviors, they emphatically feel that the framework of a computer game does not hold sufficient capacity to instruct and teach a young person how to deal with these dramatic changes and cope with such distress. What the Eveny pointed at is the importance of staying aware that the digital also has the capacity to detach knowledge from the context, to turn knowledge into controllable, calculable separate units and, by doing so, reduce expansive knowledge to a containable "it."

Perhaps, to be effective, such radical changes necessitate nonlinear responses and continuous readiness for rearrangement of strategies for human action. This is precisely what Jean Briggs (1998) highlighted in her discussion of the principles of Inuit pedagogy when emotionally charged dramas were enacted by parents in front of their offspring in order to activate autonomous decisionmaking and appropriate moral response. Each enacted drama had a plot that was built on a previous plot enacted in an earlier drama. A series of enacted dramas was not supposed to offer one definite answer to a particular situation of emotional crisis but a fusion of possibilities and options as the lessons contained in previous dramas created new lessons and posed new questions. The enacted dramas were meant to generate an understanding that there was always a space for flux and change; therefore, a young person was expected to adapt autonomous thinking and preparedness to face the far-from-simple variables-i.e., "a mosaic of dilemmas which echo, cross-cut, confirm, and negate one another; dilemmas that are never totally resolved but have to be juggled and rearranged time after time" (Briggs 1998, 209). Jean Briggs's observations resonate with the Eveny responses to Never Alone: life and rapidly changing environmental conditions do not offer one linear, definite answer; rather, a myriad of further questions and a sequence of other critical situations and dramas are bound to emerge. 
Hence, the game with its organization of digital space and structure of repetitive actions only offers an approximate digital equivalent of a natural context in which indigenous reindeer herders and hunters communicate, socialize, interact, move along the landscape, and encounter predators. For us, its greatest potential is its capacity to energize reflection and thought, which became apparent as the young Eveny discussed their opinions with Ulturgasheva.

\section{Bringing in Iñuiaq Views: Walking and Talking on the Tundra}

What struck Bodenhorn on reading these comments was the extent to which the strongest Eveny responses concerned the game itself, whereas the Inupiaq responses turned more to the supplemental material. This, we suggest, invites further consideration of the possibilities as well as the limitations of such teaching tools.

To think about this, we must shift our focus once more to reconsider the potential fit between the intentions of Never Alone and those of the Iñupiaq Learning Framework. The latter aims to foster a holistic vision of the world that recognizes that Inupiaq knowledge and Iñupiaq values (sharing, respect, cooperation, and laughing together, for instance) constitute each other. This is not conceived of as an alternative to school but rather as a significant modification of it. Within the framework, teachers are invited to bring local expertise into their teaching units not only because of what they know but also for their potential to galvanize students' interest. Students are encouraged to work together and to explore the world around them through as many modes as possible. The activities of the Pathways Project, with which Bodenhorn was involved, fit in easily with such goals. ${ }^{15}$ As with Never Alone, a major focus was on walking. We wanted to learn what students knew about their surroundings, how they responded to new information, and how they imagined their world in twenty-five years' time. Students identified places that were special to them; the beach, the tundra, and the gravel pits appeared as the places these young students most opted to visit when they had the chance. We then walked to those sites, visiting an ice cellar and chatting with the whaling captain who had extended this hospitality to us. We were accompanied by Qaiyaan Harcharek - a young Iñupiaq hunter and scientist - who regaled students with stories of how he had played on this landscape not so very long ago. One of our goals was to encourage heightened awareness of what it means to observe one's surroundings. We played "sense-around," during which a blindfolded student was interviewed about what he or she was hearing, smelling, and feeling. We experimented with seeing how many different traces of an animal we could find even if the animal itself was absent: scat, scent, bird call, feathers, footprints, remains of another animal that might have furnished a meal.

During these activities, the Iñupiaq experts created the strongest pull - the middle-aged whaling captain, who spoke about the impact of changing climatic conditions on the safety of ice cellars, and the younger whaler/scientist, whose stories included the history of epidemics (sparked by his finding skulls on the tundra when playing there as a child), the archaeology of pot-building at the gravel pit site prior to the arrival of Euro-American whalers, and knowledge of curative plants learned from his grandmother as they walked the tundra. When Bodenhorn asked one young man (who inside the classroom is clearly on the edge of adolescent disaffection) what he had found interesting during the outing, he said, simply, "Everything." 
In "Expecting the Unexpected: Canadian Inuit Training for an Experimental Lifestyle," Jean Briggs (1991) talks about how a walk in central Canada resulted in her companions wondering about the multiple potentials of the things they found along the way. The question was not "What is this for?" but rather "What else might it be for?" That open-ended creativity is exactly what we have been hearing in Eveny comments about what their young people need to learn. And in many ways, that underpinning value of imagination gave life to our Barrow walks as well. Students thought up their questions and led our discussions about the "so what" of the answers. But we need to be careful not to assume that Iñupiaq learning styles are simply about free-flowing creativity. The whaling captain was explicit that if you did not know how to treat a disused ice cellar, you could die from the toxic buildup of gases released by the permafrost. Young women learning how to braid sinew for skin boat covers may be required to redo their work many times by their teachers; if a seam were to come apart while a crew was out on the ocean, lives could be lost. The Arctic can be an unforgiving environment. One of the trickiest aspects of learning and teaching recounted to Bodenhorn in the 1980s was the balance between exacting standards that keep others safe and open-ended parameters that foster self-reliance in the face of the unexpected (Bodenhorn 1987). Both were part of the walking experience.

We are left wondering whether - to encourage young people to play with the game rather than just play the game - it might be worth shifting the parameters a bit: introducing live storytelling and encouraging players, as teams, to invent scenarios as part of the story line. Both interactive moves would bring the play out of the game box - as Brower urged - and both would, in Briggs's terms, create the spaces for open-ended responses to ambiguity and invention.

\section{The Work of a Museum Revisited: Beyond Fetish as Culture; Culture as Fetish}

Several years ago, Ann Fienup-Riordan reflected that the dominant mode of defining culture in mainstream United States was as a "thing you could have and could lose" $(1990,23)$, whereas the Nelson Islanders, with whom she continues to work, talk about ways of knowing. Similarly, Wainwright whaling captain Barry Bodfish Sr., when discussing Iñupiaq struggles with the International Whaling Commission, asked, testily, "Don't they understand, it's not the weapons we use; it's the fact that we share that makes us Iñupiaq?!" ${ }_{16}$ These ways of knowing also promote an ongoing, experimental, and flexible set of tools for engaging with the surrounding world. ${ }^{17}$ Rather than thinking about cultural values as ring-fenced and fixed, what we are hearing is the importance of openness to new possibilities.

And here we return to the subject of refugee bears - which are both real and good to think. When Veena Das (1997) talked about "critical events," she explicitly said that radical unfamiliarity requires new forms of thinking - thinking that is often not forthcoming because of the human propensity for reaching for the tried and true. Although she was talking about events such as the Partition, the explosion at Bhopal, and the assassination of Indira Gandhi, the reindeer herders would have understood her immediately-and concurred. The capacity to think in this manner needs to be learned.

The bottom line of all of these observations is that neither the medium nor the message is the key. When thinking about the work of the museum, all forms of technology (in their material as well 
as nonmaterial aspects) have the capacity to contribute to a toolbox of skills, knowledge, and things that provide northern actors with the means to engage with ever-changing conditions. It is this realization that leads us to think about Never Alone, the Iñupiaq Learning Framework, and field visits and walks on the beach with family and friends as multiple sources of understanding that become more effective as they are interconnected. All have the capacity to animate knowledge, past, present, and future, which we have suggested is central to a contemporary understanding of what the work of a museum can be.

What remains, however, are Foucauldian questions of power/knowledge: whose voice carries? Young people in many contexts experience schools as places that diminish them, often because their origins, lifeways, skills, and aspirations are not recognized as valuable. Many teachers, parents, and community organizations are currently putting considerable creative effort into reversing the destructive consequences of such diminishment-often through the innovative use of communications technologies. For the final part of this discussion, we turn briefly to an examination of the use of IT, not for cultural revival, but for cultural survival.

\section{IT, Voice, and Reaching a Wider Audience}

In our discussion of Ulturgasheva's conversations with the young Eveny, we noted the potential for the virtual to detach users from the contextual variation, which, more often than not, is a major driver in generating effective action. Major criticisms of TEK (Traditional Ecological Knowledge) have focussed on similar issues - that by decontextualizing information when storing it in virtual form, the ultimately social nature of that information can be lost (see, e.g., Cruikshank 2004; Wenzel 2004). Although the creators of Never Alone were painstaking in their commitment to creating beautiful, complex, connected, and impactful content, it is perhaps the very gameness of the game that allows for the capacity to detach.

Here again, we caution against overdetermination. In this final section, we examine the role of IT in providing an alternative means for voicing what may be suppressed by officials if using other means of communication and for connecting rather than detaching local conversations. For this, we return to the two presentations made at the recent conference already mentioned on anthropology and climate in London. Readers have already encountered Rachel Edwardson, a young Iñupiaq oral historian and filmmaker from Barrow, and T. Keimetinova, V. Keimetinov, and N. Krivoshapkin, Eveny reindeer herders. In both cases, their presentations were not about cultural revival but about cultural and political survival. Their presence in London was importantly a struggle for voice.

Edwardson - who was unable to attend - sent a virtual presentation to convey the complexities of geopolitics as they are playing out in the Alaskan Arctic to a wide, international audience. The Eveny reindeer herders used cell phones and digital cameras to capture firsthand the devastating climate events that are currently laying waste to their homeland; that record was the backbone of their London presentation. For these reindeer herders, IT provided a way of presenting plural takes on events recorded in situ, which do not require long-term editing processes. These communications technologies are considered absolutely essential for producing such plurality and are accepted as a medium of knowledge and voice rather than in any sense of game. 
In both cases, messages and motivations for using IT had nothing to do with cultural revival. The participants were in London to be heard, to have a voice about issues they consider critical to the survival of their ways of being. In this sense, the refugee bear-as representing unruly, capricious, powerful, and unfamiliar aspects of daily life-can stand for sociopolitical entities as much as climate processes.

Both Edwardson's and the Siberians' use and reuse of IT capture the scale of disaster to make very political statements. The Eveny wanted to reach the Iñupiat in order to ask their advice on how to deal with a new type of risk - i.e., the silver mining industry. For both, IT was a tool for opening up new types of conversations, reaching different and wider audiences, whether academic or indigenous. Such unheard voices can be easily jeopardized by all sorts of large political parties, regional governments, capitalist stakeholders, states, corporations, and/or extractive industries. Considerable media attention focuses on how social movements may use social media to circumvent such powerful suppressants: the Arab Spring, the multination protest led by Standing Rock Sioux, and the Parkland students all come to mind. The point we are making here is simply to emphasize the extent to which here too these media are not only means to communicate events to others but also to initiate conversations among potential users.

\section{Conclusions}

Projects incorporating visual and digital media by members of indigenous communities around the world have been documented and analyzed by social scientists (see, e.g., Christen 2005; Landzelius 2006; Wilson 2008; Geismar and Mohns 2011). Their significance for offering political voices within and beyond indigenous communities as well as providing a focus in current debates regarding the aesthetics and ethics of indigenous representation cannot be underestimated and should not be downplayed. Our present intention has been to open out both the potential and the possible limitations to such endeavors. Thus, we see Never Alone as an effort to promote alternative ways of fostering the confident sense of self that is necessary for successful learning and teaching. We agree with many activists in the field that standard modes of teaching can often detach learning processes from a wider social and cultural universe of learners; this, in turn, often diminishes the importance of vernacular knowledge for young learners (see Condon 1987; Sarris 1993; Ulturgasheva 2012). And we have noted initiatives designed to overcome this. The question remains: what catches students' attention and makes them want to learn?

In his essay "Keeping Slug Woman Alive," Sarris (1993, 153-154) explores some of the challenges facing Kashaya Pomo schools, whose students are disaffected. He highlights the importance of fostering students' critical thinking, which revolves more around understanding than control. Understanding, he argues, is dynamic and dialogical in nature, taking into account differences and responding to fluctuations of life experiences and conditions; control, in contrast, implies rule, command, exactness, calculation, and predictability. This, we suggest, is pertinent to the framework of a computer game. Resonating with the dynamics of a standard classroom, the computer game provides a setting for a circumscribed, algorithmic mode of interaction that excludes, often unintentionally, the student's experience. Therefore, for us, the limits of the digital rest on the particular chasm between life experiences, specifically the experience of living on and 
from the land and a computer game reality; this chasm may well be intensified further by rules and commands of the game determined and maintained by a calculation-focused, prediction-oriented digital technology.

Both Eveny and Iñupiaq young people responded positively to Never Alone's Iñupiaq graphics. It is precisely because of the Eveny herders' experience that they identified the potential disconnect between the rules of the game and the realities of survival in a Siberian landscape. As Brower pointed out, fewer young Iñupiat have that same experience. But as Bodenhorn's recent work with Barrow middle schoolers has revealed, these young students still value going out more than staying in with an Xbox. And they are hungry for interaction with Inupiaq expertise. That leads us to suggestions that might promote playing with the game-by bringing in hunters and storytellers early on and by encouraging teams to imagine further scenarios - rather than simply playing it.

The creators of Never Alone are promoting an increased awareness of Iñupiaq ways of perceiving, knowing, and imagining the world. It is our strong sense that by using Never Alone as a vehicle for promoting social interaction with local experts as well as providing an opportunity for students to think through situational challenges collectively, this very sexy computer game can indeed be a starting point for opening up conventional educational practices; as a means of enlivening thought, this becomes one more means through which what we have called museum work can be realized.

In many contexts, the museum is not the repository of knowledge-the elders are that. But it can serve as a critical animating link that not only has the capacity to connect past, present, and future but also resonates with many ways of being in the world: thinking, sharing, learning. In this, museum work and pedagogical work can profoundly influence each other.

\section{Notes}

1. Iñpiaq refers to the singular as well as the adjectival form referring to the inhabitants of the northern coast of what is today Alaska; Iñupiat signifies the group as a whole. (Leona Okakok, personal communication, 1980.) Material for this paper was gathered at least in part thanks to Ulturgasheva's research under grants NSF ARC 4424842 and 1207894 and Bodenhorn's research under NSF Grant 0813635 and AHRC grant AH/K006282/1.

2. See Ronald Brower, promotional interview for Never Alone, https://www .youtube.com/watch?v=gTEtK2fwKlE, published November 14, 2014.

3. See, e.g., Nancy Wachowich and William Scobie, "Uploading Selves: Inuit Digital Storytelling on YouTube," Etudies/Inuit/Studies 34, no. 2: 81-105, 2010. Visit Alaskool (http://www.alaskool.org/) for a collaborative website developed by teachers, elders, community members, and Alaska Native Studies at the University of Alaska to make cultural resources available region-wide.

4. See presentations by Rachel Edwardson on the need to avoid "silo thinking" and Eveny accounts of extreme events and the need to develop flexible skills for dealing with them in Ulturgasheva and Bodenhorn (2016). 
5. For twenty-first century work on this, see e.g., Ahrens 2010; Bennett 2013; Gable's review essay 2009, Milroy and Rozenfell 2015; and Van Oost 2002. See also Berlo and Phillips 1992 for curatorial views of representation as a central tranche of museum democratization.

6. Repatriation is often central to these discussions but is not our focus here.

7. Jeremy Swift (1978) defined fourth world peoples as those who could never hope to govern the countries they inhabit and who were held systematically in a marginal position in those countries.

8. The Living Arctic exhibit, for instance, was sponsored by the North Slope Borough and curated for the Museum of Mankind in London by Jonathan King in the late 1980s (Ingold 1988). See also Ginsburg 1991; Kovach 2009; Smith 1999; and Williamson 2011 for different approaches to voice, representation, and indigenous research. For technological engagement, see, e.g., Christen 2005. For place-based learning, see, e.g., Davidson-Hunt and O'Flaherty 2007; Grunewald and Smith, eds. 2014. For promoting young people's learning in value-reflecting ways, see, e.g., Battiste 2017; Harcharek 2013, Lynge 2006; Sarris 1993; Ulturgasheva 2012, 2014.

9. See also Fienup-Riordan 1995, 1996. See also Crowther 1992 and Jonaitis 1992-among others - on the significance of Kwakakiutl blankets as powerful in themselves in the late twentieth century.

10. See, e.g., Leona Okakok 1978 Puiguitkaat: The 1978 Elders' Conference (so that they do not forget); Waldo Bodfish with Bill Schneider 1991; Harry Brower and Karen Brewster 2004 for life histories; Fannie Akpik and Barbara Bodenhorn 2000; Bodenhorn 2000 for work sponsored by the Alaska Eskimo Whaling Commission; Rachel Edwardson 2012 for work sponsored by the NSB School District; and Raphaela Stimmelmeyer et al. 2017 on collaborative work sponsored through the North Slope Borough Department of Wildlife Management.

11. Ron Brower interview: https://www.youtube.com/watch?v=gTEtK2fwK1E; official trailer: https://www .youtube.com/watch?v=VnY21Fg5G1Y.

12. See Jana Pausauraq Harcharek and Cathy Tuquka Rexford 2015 on the development of the Learning Framework.

13. See Raymond Neakok Sr. on the differences between what he called "schooling" and "education." The latter was received from relatives in the course of learning about his own environment (see Barbara Bodenhorn 1997).

14. This was a panel convened by Ulturgasheva and Bodenhorn on "Northern Futures" and included participants from Siberia, Alaska, Canada, Iceland, and England; the RAI conference was on Anthropology and Climate, held in the British Museum. See Bodenhorn and Ulturgasheva (2016) for executive summaries of the entire panel.

15. The Pathways Project, supported by AHRC through the University of Cambridge, is a joint project between Social Anthropology and Environmental Education that focuses on young people's environmental knowledge and their relationships to their surroundings. 
16. Personal communication with Bodfish shortly before he passed away in 1999. This clash between defining culture in material or nonmaterial terms remains pertinent in 2016.

17. We have already mentioned Jean Briggs 1991; see also Bodenhorn 2000 on Iñupiaq flexibility regarding whaling technologies.

\section{References Cited}

Ahrens, Katy E. 2010. "Democratizing the Museum through Access as Visible Storage Collections." MA thesis, University of Washington.

Akipk, Fannie, and Barbara Bodenhorn, eds. 2000. Pilgallasiniq ivaluipianik: Learning to Braid 'Real' Thread. Barrow, AK: Ilisagvik College and Alaska Eskimo Whaling Commission.

Alaskool. n.d. "Online Materials about Alaska Native History, Education, Languages and Cultures.” Accessed May 16, 2018. http://www.alaskool.org/

Battiste, Marie. 2017. Decolonizing Education: Nourishing the Learning Spirit. Vancouver: University of British Columbia Press.

Bennett, Tony. 2013. Birth of the Museum: History, Theory, Politics. London: Routledge.

Berlo, Janet C., and Ruth B. Phillips. 1992. "Vitalizing the Things of the Past: Museum Representations of Native North American Art in the 1990s." Museum Anthropology 16 (1): 29-43. https://doi.org/10.1525/mua.1992.16.1.29

Bodenhorn, Barbara. 1997. "People Who Are Like Our Books: Reading and Teaching on the North Slope of Alaska." Arctic Anthropology 34 (1): 117-134. http://www.jstor.org/stable/40316428

- - - 2000. "It's Traditional to Change: A Case Study of Strategic Decision-Making on Alaska's North Slope.” Cambridge Anthropology 22 (1): 24-51.

— - - and Olga Ulturgasheva. 2016. "Northern Futures?: Climate, Geopolitics and Local Realities, Executive Summary.” Northern Notes 46 (Autumn/Winter): 30-35.

Briggs, Jean. 1991. "Expecting the Unexpected: Canadian Inuit Training for an Experimental Lifestyle.” Ethnos 19 (3): 259-287. https://www.jstor.org/stable/640523

- - - 1998. Inuit Morality Play: The Emotional Education of a Three-Year-Old. New Haven, CT: Yale University Press. 
Brightman, Marc, Vanessa Grotti, and Olga Ulturgasheva, eds. 2012. Animism in Rainforest and Tundra: Personhood, Animals, Plants and Things in Contemporary Amazonia and Siberia. New York: Berghahn Books.

Brower, Harry Jr., and Karen Brewster. 2004. The Whales They Give Themselves: Conversations with Harry Brower, Jr. Fairbanks: Alaska University Press.

Brower, Ronald. 2014. Never Alone - Iñupiaq Perspectives - Ron Brower, Sr. Published November 13, 2014, by Never Alone - Kisima Ingitchuna. https://www.youtube.com/watch?v=gTEtK2fwKlE

Christen, Kimberly. 2005. "Gone Digital: Aboriginal Remix in the Cultural Commons." International Journal of Cultural Property 12: 315-344. https://doi.org/10.1017/S0940739105050186

Condon, Richard. 1987. Inuit Youth: Growth and Change in the Canadian Arctic. New Brunswick, NJ: Rutgers University Press.

Crowther, Gillian. 1992. Haida Creative Traditions: Reconciling the Present with the Past. PhD diss., University of Cambridge.

Cruikshank, Julie. 2004. Keynote address to the Etudes/Inuit/Studies Conference: A Critique of TEK, Iqaluit (Baffin Island), Canada.

Das, Veena. 1997. Critical Events: An Anthropological View of Contemporary India. Delhi: Oxford University Press.

Davidson-Hunt, Ian J., and R. Michael O'Flahert. 2007. "Researchers, Indigenous Peoples, and Place-Based Learning Communities." Society and Natural Resources: An Internal Journal 20 (4): 291-305. https://doi.org/10.1080/08941920601161312

Edwardson, Rachel. 2012. History of the Iñupiat: Project Chariot. Produced for the Alaska Native Education Program, operated by the North Slope Borough School District.

Edwardson, Rachel. 2016. Presentation at Northern Futures Session: Anthropology and the Climate Conference, British Museum, London, on May 23, 2016.

Fienup-Riordan, Ann. 1995. Boundaries and Passages: Rule and Ritual in Yup'ik Oral Tradition. Norman: University of Oklahoma Press.

- - - 1996. Agayuliyaraput (Our Way of Making Prayer): The Living Tradition of Yup'ik Masks. Seattle: University of Washington Press.

- - - 1998. "Yup'ik Elders in Museums: Fieldwork Turned on Its Head." Arctic Anthropology 5 (2): 49-58. https://www.jstor.org/stable/40316487 
- - . 1999. "Collaboration on Display: A Yup'ik Eskimo Exhibit at Three National Museums." American Anthropologist 101(2): 339-348.

https://doi.org/10.1525/aa.1999.101.2.339

Gable, Eric. 2009. "Review Essay: Museology as Cultural Studies.” Museum Anthropology 32 ( 1): 51-54. https://doi.org/10.1111/j.1548-1379.2009.01022.x

Geismar, Haidi, and William Mohns. 2011. "Social Relationships and Digital Relationships: Rethinking Database at the Vanuatu Cultural Centre." Journal of the Royal Anthropological Institute 17 (s1): S133-S155. https://doi.org/10.1111/j.14679655.2011.01693.x

Ginsburg, Faye. 1991. “Indigenous Media: Faustian Contract or Global Village?” Cultural Anthropology 6 (1): 92-112. https://www.jstor.org/stable/656496

- - . 2008. "Rethinking the Digital Age." In Global Indigenous Media: Cultures, Poetics, and Politics, edited by Pamela Wilson and Michelle Stewart, 287-306. Durham, NC: Duke University Press.

Grunewald, David A., and Gregory A. Smith, eds. 2014. Place-Based Education in the Global Age: Local Diversity. London: Psychology Press.

Hallowell, Alfred Irwing. 1926. "Bear Ceremonialism in the Northern Hemisphere." American Anthropologist 28 (1): 1-175. https://doi.org/10.1525/aa.1926.28.1.02a00020

Ingold, Tim. 1988. “Living Arctic.” Anthropology Today 4 (4): 14-17. https://doi.org/10.2307/3032991

Jensen, H., and Polly Sargetti. 1986. Robes of Power: Totem Poles on Cloth. Vancouver: University of British Columbia Press.

Jonaetis, Aldona. 1992. "Chiefly Feasts: The Enduring Kwakiutl Potlatch: From Salvage Anthropology to a Big Apple Button Blanket." Curator: The Museum Journal 35 (4): 255-267. https://doi.org/10.1111/j.2151-6952.1992.tb00763.x

Keimetinova, Taisiia, Vasilii Keimetinov, and Nikolai Krivoshapkin. 2016. "Weather, Floods and Forest Fires in Northeastern Siberia," translated by Olga Ulturgasheva. Panel on "Northern Futures? Climate, Geopolitics and Local Realties," moderated by Olga Ulturgasheva and Barbara Bodenhorn. [Royal Anthropological Institute Conference on] "Anthropology, Weather and Climate Change," British Museum, London, May 27-29, 2016.

Kovach, Margaret. 2009. Indigenous Methodologies: Characteristics, Conversations, and Contexts. Toronto: University of Toronto Press. 
Kwon, Heonik. 1999. "Play the Bear: Myth and Ritual in East Siberia." History of Religions, 38 (4): 373-387. http://www.jstor.org/stable/3176324

Landzelius, Kyra, ed. 2006. Native on the Net: Indigenous and Diasporic Peoples in the Virtual Age. London: Routledge.

Lynge, Aviaja. 2006. The Best Colony in the World. http://www.rethinking-nordiccolonialism.org/files/pdf/ACT2/ESSAYS/Lynge.pdf

Milroy, A. K., and A. C. Rozenfelds. 2015. "Democratizing the Collection: Paradigm Shifts in and through Museum Culture." Australian Journal of Popular Culture 4 ( 2-3): 115-130. https://doi.org/10.1386/ajpc.4.2-3.115_1

Okakok, Kisautaq Leona, ed. and trans. 1981. Puiguitkaat: The 1978 Elders' Conference. Barrow, AK: North Slope Borough.

Puasauraq, Jana Harcharek, and Cathy Taquak Rexford. 2015. "Remembering Their Words; Evoking Kinguniivut: The Development of the Iñupiaq Learning Framework." Journal of American Indian Education 54 (2): 9-28.

Sarris, Greg. 1993. Keeping Slug Woman Alive: A Holistic Approach to American Indian Texts. Berkeley: University of California Press.

Smith, Linda Tuhiwai. 1999. Decolonizing Methodologies: Research and Indigenous Peoples. New York: Zed Books.

Stimmelmeyer, Raphaela, Billy Adams, Qaiyaan Harcharek, Michael Pederson, Harry Brower Jr., and Taqulik Hepa. 2017. "Change is the Only Constant: Community Driven Questions, Indigenous Knowledge (IK) and Western Science Working Together-A Northern Perspective." American Geophysical Union fall meeting. Abstract C13H-06.

Swift, Jeremy. 1978. "Marginal Societies at the Modern Frontier in Asia and the Arctic." Development and Change 9 (1): 13-18. https://doi.org/10.1111/j.14677660.1978.tb00796.x

Thrift, Nigel. 2004. "Movement-Space: The Changing Domain of Thinking Resulting from the Development of New Kinds of Spatial Awareness." Economy and Society 33 (4): 582604. https://doi.org/10.1080/0308514042000285305

Ulturgasheva, Olga. 2012. Narrating the Future in Siberia: Childhood, Adolescence and Autobiography among Young Eveny. Oxford: Berghahn Books.

- - - 2014. "Attaining Khinem: Challenges, Coping Strategies and Resilience among Eveny Adolescents." Transcultural Psychiatry 51: 632-650. https://doi.org/10.1177/1363461514546246 
- - . 2016. "Spirit of the Future: Movement, Kinetic Distribution and Personhood among Eveny." Social Analysis 60 (1): 56-73. https://doi.org/10.3167/sa.2016.600105

- - - . and Barbara Bodenhorn. 2016. "Northern Futures: Climate, Geopolitics and Local Realities, Shortened Executive Summary." Witness the Arctic: Chronicle of the NSF Arctic Sciences Section / ARCUS 20, no. 3: 23-30.

— - _., Stacy Rasmus, Lisa Wexler, Kristine Nystad, and Michael Kral. 2014. "Arctic Indigenous Youth Resilience and Vulnerability: Comparative Analysis of Adolescent Experiences and Resilience Strategies across Five Arctic Indigenous Communities." Transcultural Psychiatry 51(5): 735-756.

- - _., Stacy Rasmus, and Phyllis. Morrow. 2015. "Collapsing the Distance: Indigenous Youth Engagement in a Circumpolar Study of Youth Resilience.” Arctic Anthropology 52 (1): $50-60$.

Van Oost, Olga. 2002. "Museum Participation in a Network Society: A Reflection.” Working paper 2004-01. Sternspunt re-creatif Vlaanderen.

Vitebsky, Piers. 2005. Reindeer People: Living with Animals and Spirits in Siberia. London: Harper Collins.

Wachowich, Nancy, and Willow Scobie. 2010. "Uploading Selves: Inuit Digital Storytelling on YouTube.” Études/Inuit/Studies 34 (2): 81-105.

Wenzel, George. 2004. "From TEK to IQ: Inuit Qaujimajatuqangit and Inuit Cultural Ecology." Arctic Anthropology 41 (2): 238-250. https://www.jstor.org/stable/40316631

Williamson, Karla. 2011. Inherit My Heaven: Kalaallit Gender Relations. Inussuk Arctic Journal 1. Nuuk, Greenland: Department of Culture, Education, Research and Church, Government of Greenland.

Wilson, Shawn. 2008. Research Is Ceremony: Indigenous Research Methods. Winnipeg, MB: Fernwood Publishing.

Barbara Bodenhorn is Fellow Emerita of Pembroke College at the University of Cambridge where she is affiliated with the Department of Social Anthropology. Her work focuses on environmental knowledge and learning processes, fourth world politics and resource management, kinship, economics and globalization. Her projects have been set in Mexico, Alaska (USA), and the United Kingdom. Her most recent book is Recovering the Human Subject, co-edited with James Laidlaw and Martin Holbraad (New York: Cambridge University Press, 2018). 
Olga Ulturgasheva is a Lecturer in the Department of Social Anthropology at the University of Manchester. She has carried out ethnographic research on childhood and adolescence, narrative and memory, animist and nomadic cosmologies, and reindeer herding and hunting in Siberia and Alaska. Her most recent volume is Animism in Rainforest and Tundra, co-edited with Marc Brightman and Vanessa Elisa Grotti.(Oxford: Berghahn, 2014). And she is the author of Narrating the Future in Siberia: Childhood, Adolescence and Autobiography among the Eveny. (Oxford: Berghan. 2012).

https://doi.org/10.14434/mar.v12i2.23184 